\title{
An in vitro study of the prebiotic properties of Xylooligosaccharide (XOS) and organoleptic evaluation of XOS added Prawn patia and Black rice kheer.
}

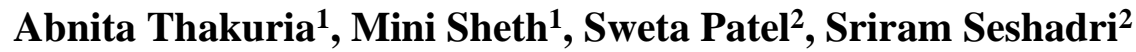 \\ ${ }^{1}$ Department of Foods and Nutrition, Faculty of Family and Community Sciences, The \\ Maharaja Sayajirao University of Baroda, Vadodara-390002, Gujarat, India, ${ }^{2}$ Institute of \\ Science, Nirma University, Ahmedabad, Gujarat, India
}

Corresponding Author: Abnita Thakuria, $\mathrm{PhD}$ research scholar, Department of Foods and Nutrition, Faculty of Family and Community Sciences, The Maharaja Sayajirao University of Baroda, Vadodara-390002, Gujarat, India

Submission Date: December $12^{\text {th }}, 2019$ Acceptance Date: January $20^{\text {th }}$, 2020, Publication Date: January $31^{\text {st }}, 2020$

Citation: Thakuria A, Sheth M, Patel S, Sriram. An in vitro study of the prebiotic properties of Xylooligosaccharide (XOS) and organoleptic evaluation of XOS added Prawn patia and Black rice kheer. Bioactive Compounds in Health and Disease 2020; 3(1): 1-14 DOI: https://doi.org/10.31989/bchd.v3i1.682

\begin{abstract}
Background: There is emerging evidence that functional foods ingredients can have an impact on a number of gut related diseases and dysfunctions [1]. A prebiotic is a selectively fermented ingredient that allows specific changes, both in the composition and/or activity in the gastrointestinal microflora that confers health benefits [2]. Besides providing the health benefits, prebiotics are known to extend technological advantages in favour of improved organoleptic qualities of the food products. Xylooligosaccharides (XOS) is a stable prebiotic which can withstand heat up to $100^{\circ} \mathrm{C}$ under acidic conditions $(\mathrm{pH}=2.5-8)$ and has a potential to be incorporated into food products [3]. However, its prebiotic properties needs to be established in terms of bile resistance, acid tolerance, fermentability to produce short chain fatty acids (SCFA) and growth of Lactobacillus plantarum, Bifidobacterium adolescentis and Escherichia coli. XOS also needs to be exploited for its potential to be incorporated into various food products and study their organoleptic properties similar to fructooligosaccharides (FOS), which has proven technological benefits in terms of its miscibility and organoleptic qualities.
\end{abstract}

Objective: Several prebiotics such as FOS, (Galactooligosaccharide) GOS, and inulin have been recently recognized for their health promoting abilities. XOS is yet another emerging prebiotic that needs to be explored for its prebiotic potential especially in terms of its acid tolerance, bile resistance and ability to get fermented by the probiotic bacteria. Produce health promoting short chain fatty acids as well as its potential to be added to food products. There is little literature available on prebiotic potential of XOS and its organoleptic properties upon its addition into foods. Therefore, this study was undertaken to determine the prebiotic properties 
of XOS and to study the organoleptic properties of XOS upon its addition on a few Indian traditional foods (Prawn patia and Black rice kheer).

Results: No degradation of XOS was observed on its exposure to bile at $0 \mathrm{~h}, 1.5 \mathrm{~h}$ and $3 \mathrm{~h}$ with bile concentration $0.5 \%, 1 \%$ and $1.5 \%$. XOS recovery was observed to be $100 \%$ on its exposure to $\mathrm{pH} 1.5,2$ and 3 at 0 hours. At 1.5 hours it was found to be $98.4 \%, 98.9 \%$ and $97.9 \%$ at $1.5 \mathrm{pH}, 2 \mathrm{pH}$ and $3 \mathrm{pH}$ respectively and $96.2 \%, 97.3 \%$ and $96.3 \%$ upon its exposure to $1.5 \mathrm{pH}$, $2 \mathrm{pH}$ and $3 \mathrm{pH}$ respectively at 3 hours. Growth of Lactobacillus plantarum and Bifidobacterium adolescentis was higher (OD 0.71) and (OD 0.75) up to $2 \%$ when compared to glucose ( $\mathrm{p} \leq 0.01$ ), whereas, growth of Escherichia coli (OD 0.4) was restricted upon addition of XOS when compared to glucose $(\mathrm{p} \leq 0.01)$. Acetate was produced the most, followed by Propionate and Butyrate. Organoleptic evaluation revealed no significant difference in XOS added Prawn patia and Black rice kheer at all levels of addition (5\%,8\% and 10\%). Hence, addition of XOS to these two products was well accepted by the panellists up to $10 \%$ level of addition.

Conclusions: This study has successfully established the prebiotic potential of XOS in terms of acid tolerance, bile resistance, growth of probiotic bacteria and production of SCFA. XOS was well accepted in both the food products at all the three levels of incorporation, i.e. $5 \%, 8 \%$ and $10 \%$. Limited researches have been conducted on prebiotic XOS. Therefore, for discussion references were taken with regards to other prebiotics such as FOS, inulin etc. Further studies can be undertaken to demonstrate the clinical efficacy of XOS intake with respect to various non-communicable diseases.

Keywords: Xylooligosaccharide, prebiotic, sensory evaluation, Galactooligosaccharide (GOS), SCFA, probiotic bacteria.

\section{INTRODUCTION:}

The concept of prebiotic was introduced around 20 years ago, despite several revisions to the original definition which was introduced in 1995 by Glenn Gibson and Marcel Roberfroid, the scientific community continued to debate what it means to be a prebiotic [4]. Prebiotics are defined as a selectively fermented ingredient that allows specific changes, both in the composition and/or activity in the gastrointestinal microflora that confers benefits upon host well being and health [2]. It is also defined as a non digestible compound that, through its metabolization by microorganisms in the gut, modulates the composition and/or activity of the gut microbiota, thus conferring a beneficial physiologic effect on the host [5].

Several studies have confirmed that prebiotics are a valid approach to the dietary manipulation of the colonic micro flora and thereby improved glycemic, lipemic, inflammatory biomarkers and increased the production of short chain fatty acids [6,7,8].

The prebiotic potential of XOS have been explored the least whereas, inulin, FOS, resistance starch etc. have been explored to a great extent. Therefore, this study was intended to explore the prebiotic potential of XOS with regards to acid tolerance, bile resistance, growth of probiotic bacteria such as Lactobacillus plantarum and Bifidobacterium adolescentis, production of SCFA namely, acetate, butyrate and propionate and to evaluate the organoleptic properties and acceptability upon its addition in Black rice kheer and Prawn patia.

Kheer is a rice pudding, originating from the Indian subcontinent, made by boiling milk and sugar with one of the following: rice, broken wheat, tapioca, vermicelli, or sweet corn. It is flavored with cardamom, raisins, saffron, cashews, pistachios, almonds or other dry fruits 
and nuts. It is typically served during a meal or as a dessert. Prawn patia is one of those dishes that combine every flavor we normally have separately into one. There are sweet, spicy, tangy and hot notes that work wonderfully with each other. One dessert and one from the main course was selected for value addition using XOS.

\section{METHODS AND MATERIALS}

\section{Materials for bile resistance and acid tolerance test of XOS}

Commercial XOS derived from corn cobs were purchased from Hangzhou Focus Corporation. (Hangzhou, China) and was 95\% pure, Ox bile and hydrochloric acid procured from Sigma.

\section{Bile resistance test of XOS}

Ox bile (1g) was dissolved in 100ml DI water and stirred well till it dissolved. Bile solution was made up to bile level $0.5 \%, 1 \%$ and $1.5 \%$ using Ox bile (Sigma) and 5g XOS was added to the bile solutions at room temperature $\left(25^{\circ} \mathrm{C}\right)$. These solutions were used to study bile resistance of XOS at 0 hour, 1.5 hours and 3 hours. The samples were filtered and 20 micro litre each were used for the HPLC analysis. This method was modified in house with reference to [9].

\section{Acid tolerance test of XOS}

XOS $(5 \mathrm{~g})$ were dissolved in $100 \mathrm{ml}$ DI water at room temperature $\left(25^{\circ} \mathrm{C}\right)$ and stirred well till it dissolved. X ml (QS) Hydrochloric acid solution was added to the solution to adjust $\mathrm{pH}=1.5$, 2.0 and 3.0. These solutions were used to study acid tolerance of XOS at 0 hour, 1.5 hours and 3 hours. The samples were filtered and 20 micro litre each were used for the HPLC analysis. This method was modified in house with reference to [9].

Materials for determination of prebiotic effect of XOS on L. plantarum, B. adolescentis, E. coli and SCFA analyses using HPLC

Commercial XOS derived from corn cobs were purchased from Hangzhou Focus Corporation. (Hangzhou, China) and was $95 \%$ pure. The degrees of polymerization of the XOS mixture ranged from xylobiose to xylohexaose. All chemicals were purchased from Sigma-Aldrich, India. Bacterial culture for Lactobacillus plantarum strain was purchased from MTCC repository, Bifidobacterium adolescentis strain from National collection of Dairy culture, National Institute of Dairy Research, Karnal. Escherichia coli were isolated from sewage at Institute of Science, Nirma University.

\section{Bacterial strains}

Lactobacillus plantarum strain (MTT2621), Bifidobacterium adolescentis strain (NCDC236) were used in the present study. The bacterial pathogen used was Escherichia coli.

\section{Prebiotic effect of XOS on L. plantarum, B. adolescentis and E. coli}

Lactobacillus plantarum was grown in MRS broth in anaerobic jar, Bifidobacterium adolescentis in MRS broth along with $0.05 \%$ cysteine in anaerobic jar and Escherichia coli in Luria-Bertani (LB) broth at $37^{\circ} \mathrm{C}$ for 24 hours. After 24 hours, each bacterium was allowed to grow with XOS concentration $0.5 \%, 1 \%, 2 \%, 3 \%$ and $4 \%$. The bacteria were grown on their respective media such as MRS agar and Luria broth without XOS as negative control. 10\%v/v inoculation was added from the active culture having OD between 0.08 and 0.1 at $620 \mathrm{~nm}$. 
These were then incubated at $37^{\circ} \mathrm{C}$ for 24 hours. After 24 hours, readings were taken in Spectrophotometer (Agilent, model no: carry 60) at 620nm.Prior to each OD measurement the flasks were carefully shaken. The concentration of XOS which gave maximum OD for each bacterium was further chosen for SCFA analysis using HPLC. All measurements were performed in duplicates.

\section{SCFA analyses using HPLC}

To evaluate the efficiency of the fermentation of XOS by Lactobacillus plantarum strain (MTT2621), Bifidobacterium adolescentis strain (NCDC236) and E. coli, HPLC was performed. Acetic, Butyric and propionic acids, products of the XOS fermentation, can be detected in the growth medium and quantified by HPLC. The first step of the experimental setup was choosing the appropriate column for efficient separation of the analytes. The column Phenyl hexyl, $100 \times 4.6 \mathrm{~mm}$ (Agilent technologies, USA) was chosen as it was prepared for separation of small polar compounds such as short-chain fatty acids. This HPLC consists of UV210 detector (Shimadzu, Kyoto, Japan) connected to a recorder. Separation of the analytes took place in the aforementioned Phenyl hexyl column. The peaks for analysis were obtained in the computer software connected to it.

The 24-hour old culture was centrifuged at 7,000 rpm for 5 minutes. Supernatant was diluted (1:1) in buffer containing $2.5 \mathrm{pH}$ water using $\mathrm{H}_{3} \mathrm{PO}_{4} .10 \mathrm{mg} / \mathrm{ml}$ of standards of acetate, butyrate and propionate (HPLC grade, Sigma) were run at $1 \mathrm{mg} / \mathrm{ml}$ flow rate in the HPLC till 15 minutes and $20 \mu 1$ of samples/standard were injected in phenyl hexyl column (Agilent). Detection wavelength was $210 \mathrm{~nm}$ and recording range was set to 0.2 absorbance unit's full scale. Prior to use, the mobile phase and samples were filtered through $0.2 \mathrm{um}$ filter prior to injecting the samples in the column. Graph 1 shows the area of standard Acetate, Butyrate and Propionate. Area was calculated for the standards and SCFA samples were calculated based on the area of standards.

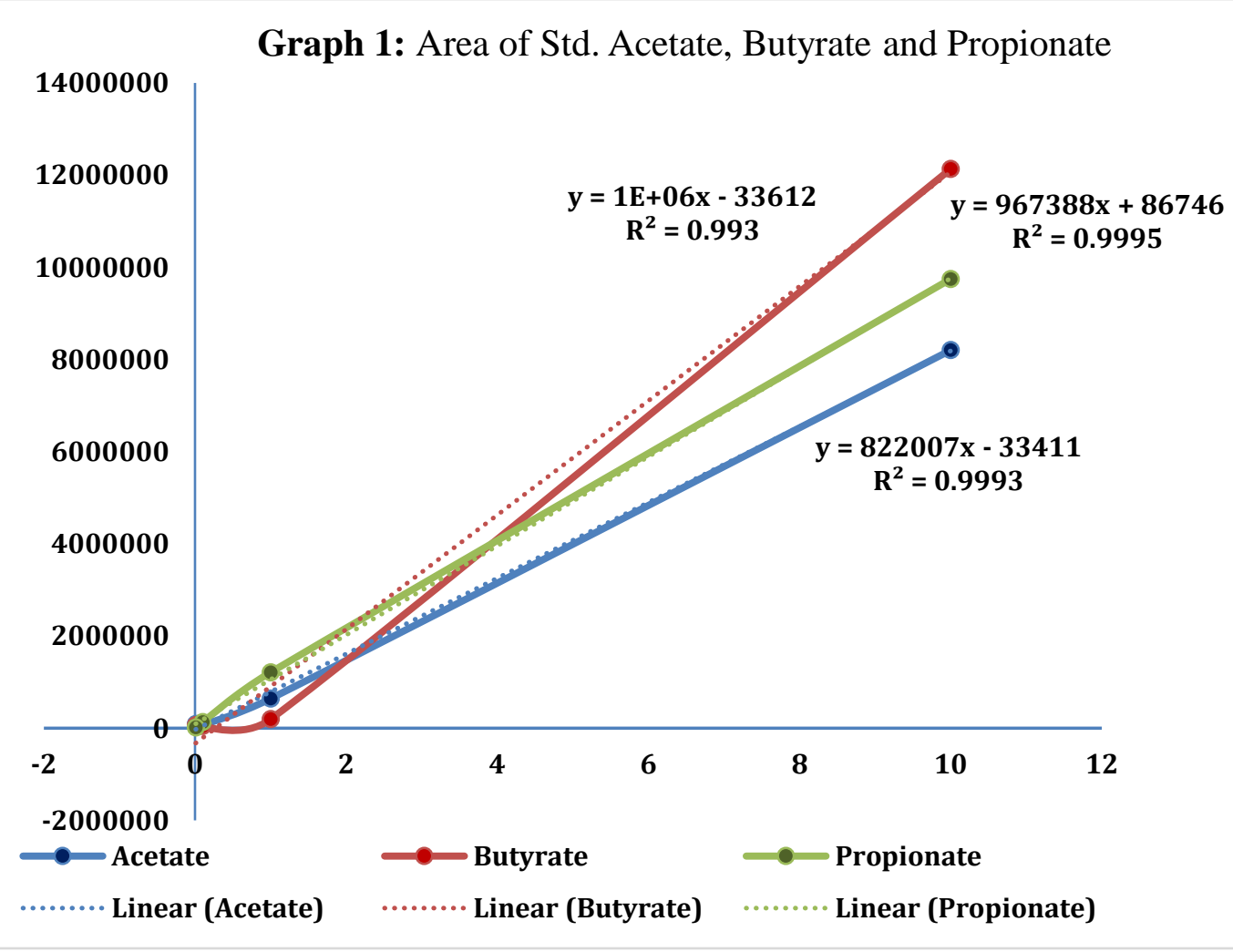




\section{PROCUREMENT OF RAW MATERIALS}

\section{For Black rice kheer:}

Black rice was procured directly from a farmer from Sonitpur district, Assam, India. Amul Taaza milk, sugar, cashews, almonds, raisins were procured from a supermarket in Guwahati, Assam.

\section{For Prawn patia:}

Deveined medium sized prawns, mustard oil, curry leaves, onion, small green chillies, tomato puree, ginger, garlic, red chilli powder, turmeric powder, cumin powder, granulated sugar, vinegar and salt were procured were procured from a supermarket in Guwahati, Assam.

Commercial XOS derived from corn cobs were purchased from Hangzhou Focus Corporation. (Hangzhou, China).

\section{Preparation of black rice kheer}

Ingredients:

Black rice $-30 \mathrm{~g}$

Milk - 250ml

Sugar $-30 \mathrm{~g}$

Almonds chopped $-1 / 2$ tbsp

Cashew nuts chopped $-1 / 2$ tbsp

Raisins - 1 tsp

\section{Preparation:}

Black rice was washed under running water till water runs clear. Rice was soaked in enough water overnight. Nuts were chopped and kept aside.

\section{Black rice kheer recipe:}

Milk was poured in a heavy bottom pan and the stove was turned on at medium flame. Milk was brought to a boil. Rice was added once the milk started boiling. It simmered on low-medium heat 25-30 minutes with continuous stirring. Thirty grams of sugar and chopped cashews, almonds and raisins was added to it and mixed well. It simmered for 8-10 minutes. The stove was turned off when the Kheer was ready. Sample A was the standard recipe with $0 \mathrm{~g}$ XOS and 30g sugar. Sample B had $5 \mathrm{~g}$ XOS and $25 \mathrm{~g}$ sugar, Sample C had 8g XOS and 22g sugar and Sample D had 10g XOS and 20g sugar.

\section{Preparation of prawn patia}

Ingredients:

Vegetable oil- 2 tbsps

Finely chopped medium sized onion- 1 no.

Chopped green chillies- 4 nos.

Tomato puree- $100 \mathrm{~g}$

Ginger-garlic paste- 1 tbsp

Red chilli powder- $1 \frac{1 / 2}{2}$ tsp

Turmeric powder- 1 tsp

Cumin powder- 1 tsp

Granulated sugar- $30 \mathrm{~g}$

Vinegar- $1 \frac{1}{2}$ tbsp

Salt- as preferred

Medium sized deveined frozen prawns (Sumeru) - 1 cup 


\section{Preparation:}

Frozen prawns were thawed. Onions, chillies were peeled, washed and chopped.

\section{Prawn patia recipe:}

Mustard oil was heated in a skillet over medium-high heat until simmering. Chopped onions were added and stirred until it turned light brown. Green chillies were added and stirred for a minute. Tomato puree was added and continued stirring until oil separated from the onion tomato mix. Ginger-garlic paste, red chilli, turmeric and cumin were added and stirred ensuring that the mixture doesn't stick to the bottom. Sugar, vinegar and water was added and cooked till the rawness of the tomato is gone. It was seasoned with salt to taste. Prawns were added, stirred and cooked for 10 more minutes until the prawns were cooked. The stove was turned off when it was ready. Sample A was the standard recipe with 0g XOS and 30g sugar. Sample B had 5g XOS and 25g sugar, Sample C had $8 \mathrm{~g}$ XOS and 22g sugar and Sample D had 10g XOS and 20g sugar.

\section{Sensory evaluation}

Thirty panelists were screened in three successive trials through threshold test at The Institute of Hotel Management, Catering Technology and Applied Nutrition, Guwahati, Assam. Sensory evaluation was carried out on Black rice kheer and Prawn patia samples containing different $0 \mathrm{~g}, 5 \mathrm{~g}, 8 \mathrm{~g}$ and $10 \mathrm{~g}$ of XOS. Out of thirty screened panelists, 25 semi trained panelists were selected using the sensitivity threshold test. The panel members were asked to fill the questionnaire and rate the samples for color and appearance, texture, taste and mouthfeel, aftertaste and overall acceptability using a composite score analysis in triplicates [10].

\section{STATISTICAL ANALYSIS}

The HPLC analysis of XOS recovery on bile resistance and acid tolerance were conducted in duplicates for each of the samples at $0.5 \%, 1 \%$ and $1.5 \%$ bile concentration and $1.5 \mathrm{pH}, 2 \mathrm{pH}$ and $3 \mathrm{pH}$ respectively. The effect of incubation period on recovery of XOS was conducted at 0 hour, 1.5 hours and 3 hours. Growth of bacteria was conducted in triplicates and OD was measured for each of the samples. Production of SCFA was also analyzed using HPLC. Data was collected and analyzed by using one-way analysis of variance (ANOVA). The significant differences between tests were set at $\mathrm{p} \leq 0.05$. All statistical analyses were performed using Microsoft office excel 2007. Chi square was also used to determine if statistical difference $(p<0.05)$ existed.

\section{RESULTS AND DISCUSSION}

\section{Bile resistance test of XOS:}

No degradation of XOS was observed on exposure of XOS to bile at 0 hour, 1.5 hours and 3 hours with bile concentration $0.5 \%, 1 \%$ and $1.5 \%$. The tests were carried out in duplicates. A study on $\mathrm{pH}$ stability of prebiotic non-digestible wheat bran-derived arabinoxylooligosaccharides (AXOS), xylooligosaccharides (XOS)-and chicory root inulinderived fructooligosaccharides (FOS) were compared. Decomposition was revealed at alkaline $\mathrm{pH}(\mathrm{pH}$ 11.0) for all three preparations tested. The short chain oligosaccharides, XOS and FOS were more sensitive to alkaline decomposition than were the longer chain AXOS, the latter 
being the result of the higher abundance of reducing ends in short chain oligosaccharide preparations [2].

\section{Acid tolerance test of XOS:}

As shown in table 1, XOS recovery was observed to be $100 \%$ on its exposure to $\mathrm{pH} 1.5,2$ and 3 at 0 hour. At 1.5 hours recovery of XOS was found to be $98.4 \%, 98.9 \%$ and $97.9 \%$ at $1.5 \mathrm{pH}$, $2 \mathrm{pH}$ and $3 \mathrm{pH}$ respectively. XOS recovery was $96.2 \%, 97.3 \%$ and $96.3 \%$ on its exposure to $1.5 \mathrm{pH}, 2 \mathrm{pH}$ and $3 \mathrm{pH}$ respectively at 3 hours. The tests were carried out in duplicates.

At pH 2.0 and 3.0, hydrolysis of oligosaccharide linkages took place, with FOS being the most acid-sensitive component [2]. Recoveries were 100\%, $91 \%$ and $113 \%$ for the supplemented muffin, cookie and nutrition bar, respectively at $3.5 \mathrm{pH}$. For the breakfast cereal, only $47 \%$ of the supplemented FOS remained after extrusion at optimal conditions (170 rpm and $140{ }^{\circ} \mathrm{C}$ ) [9]. Whereas, recoveries of Inulin at $\mathrm{pH} 3.5$ were $106 \%, 103 \%$ and $107 \%$ and $126 \%$ obtained from the supplemented extruded cereal, nutrition bar, sports drink and muffins, respectively [9].

Another study on evaluation of the prebiotic effects of citrus pectin hydrolysate (PEH), it was found that when $\mathrm{pH}$ was reduced to 3.2, populations of the tested probiotics did not decrease significantly ( $p>0.05$ ) for all treatments. The tested probiotics showed significantly higher acid tolerance and survival populations in the media supplemented with PEH than glucose. This indicated that PEH should contain some oligosaccharides which assisted the probiotics in acid tolerance and survival ability, while glucose did not [11].

\begin{tabular}{|l|c|c|c|}
\hline \multicolumn{4}{|c|}{ Table 1: XOS recovery at different levels of pH } \\
\hline $\mathbf{p H}$ & $\mathbf{0 h}$ & $\mathbf{1 . 5 h}$ & $\mathbf{3 h}$ \\
\hline $\mathbf{1 . 5 p H}$ & $100 \%$ & $98.41 \%$ & $96.29 \%$ \\
\hline $\mathbf{2 p H}$ & $100 \%$ & $98.94 \%$ & $97.32 \%$ \\
\hline $\mathbf{3 p H}$ & $100 \%$ & $97.93 \%$ & $96.39 \%$ \\
\hline
\end{tabular}

A review was reported on the digestibility of Inulin and Oligofructose which found an average recovery of $88 \%$ in human upper intestine [12].

There is little available information in the literature on bile resistance, acid tolerance properties of XOS in vitro.

\section{Prebiotic effect of XOS on the growth of L. Plantarum, B. Adolescentis and E. coli}

As seen in figure 1, the growth of Lactobacillus plantarum (LP) and Bifidobacterium adolescentis (BA) were higher at $0.5 \%, 1 \%$ and $2 \%$ of XOS addition. For Escherichia coli (E.coli) the growth gradually decreased as the concentration of XOS increased from $0.5 \%$ to $2 \%$. Since $0.5 \%, 1 \%$ and $2 \%$ levels of XOS concentration gave better or almost equivalent growth of Lactobacillus plantarum (LP), Bifidobacterium adolescentis(BA) and reduced the growth of Escherichia coli (E. coli). Therefore, $0.5 \%, 1 \%$ and $2 \%$ levels of XOS concentration samples were chosen for production of short chain fatty acids (SCFA) and its analysis. 


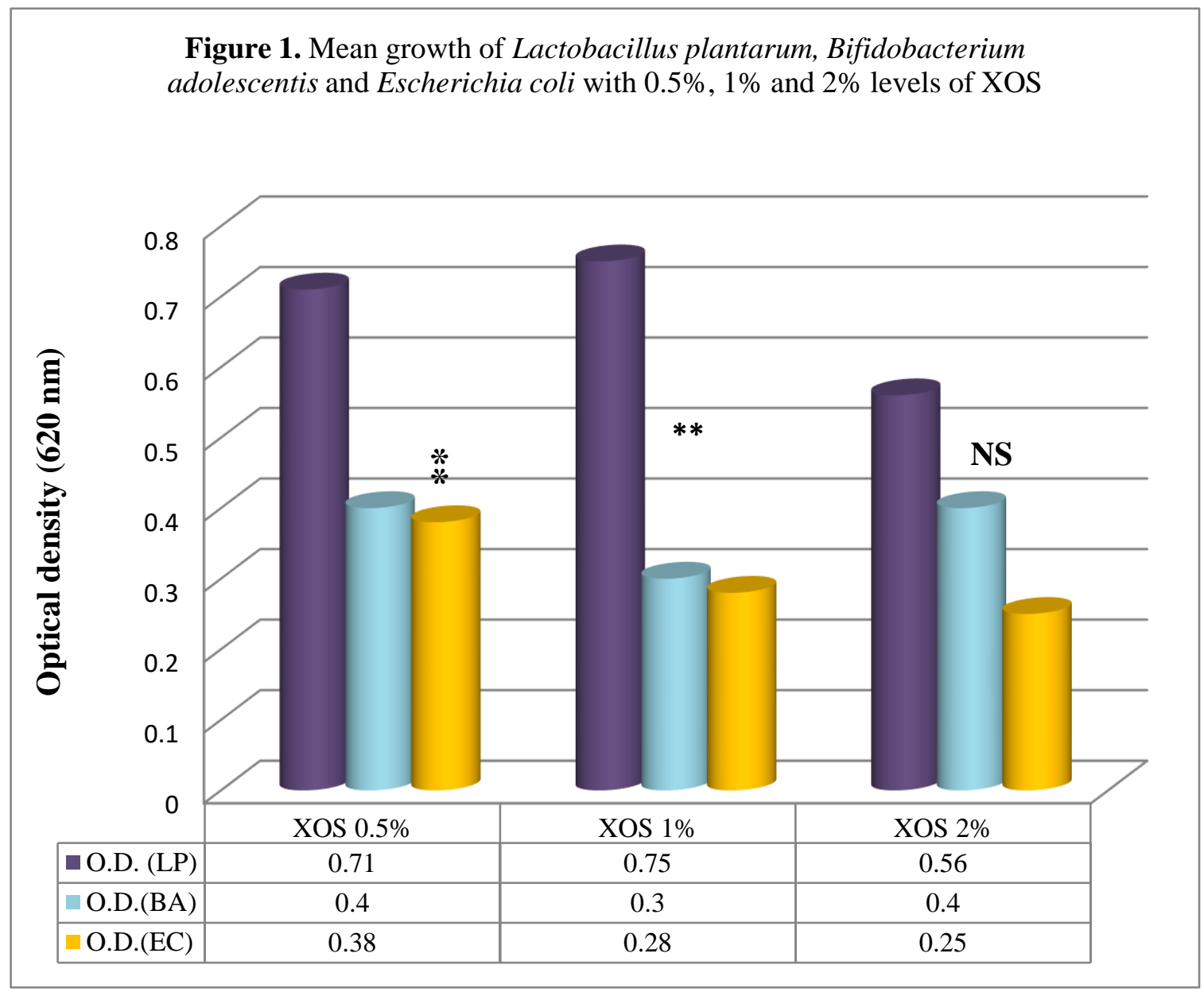

Significant at ${ }^{*} \mathrm{p} \leq 0.05, * * \mathrm{p} \leq 0.01, * * * \mathrm{p} \leq 0.001, \mathrm{NS}$ : non significant

Figure 1 shows mean growth of Lactobacillus plantarum was more with $0.5 \%$ and $1 \%$ XOS concentration at $\mathrm{p} \leq 0.01$, growth of Bifidobacterium adolescentis was seen to be same with $0.5 \%$ and $2 \%$ XOS concentration at $\mathrm{p} \leq 0.01$ and growth of Escherichia coli was the least with $1 \%$ XOS.

A study on functional properties of commercial prebiotics showed the increase in cell density of L. paracasei 1195 grown on Raftilose P95, Inulin-S, and Raftiline HP were significantly higher $(\mathrm{p} \leq 0.05)$ than for glucose. B. bifidum NCI had a significantly higher $(\mathrm{p} \leq 0.05)$ increase in cell density when grown on NutraFlora P-95 and Raftilose P95 than on glucose. Also, the increase in cell densities of L. plantarum 4008 and L. acidophilus 33200 were significantly larger $(\mathrm{p} \leq 0.05)$ for purified GOS than for glucose [13].

An in vitro study investigated the potential prebiotic effect of natural (NS) and blanched (BS) almond skins, the latter being a by-product of the almond-processing industry. Their study concluded that dietary fiber from almond skins altered the composition of gut bacteria and that almond skins resulting from industrial blanching could be used as potential prebiotics [14].

A study on the prebiotic activity of XOS obtained from corncob and reagent grade xylan were tested in L. brevis, L. plantarum, L. acidophilus, L. rhamnosus cultures, and in a coculture with Escherichia coli as a challenge microorganism to prove the bacteriostatic activity of lactobacilli strains. Xylooligosaccharides stimulated L. brevis and L. plantarum growth: 
these microorganisms grew faster than the other lactobacilli strains. L. acidophilus grew better in the presence of XOS and maintained the absorbance of the culture. In the co-culture in presence of both XOS the challenge microorganism did not grow; lactobacilli colonies appeared in MRS agar. No colonies of E. coli grew in EMB plaques [15].

\section{SCFA production analysis during fermentation in vitro}

Lactobacilli and Bifidobacteria ferment carbohydrates through a pathway mediated by the glycolytic enzymes in which the main end products are SCFA [16]. Butyrate, Propionate and Acetate are the major SCFA produced during fermentation of carbohydrates in the large bowel [17].

A study on bioactive xylooligosaccharides from wheat bran soluble polysaccharides reported that Acetate was the chief SCFA liberated due to in vitro fermentation of xylooligosaccharides [17].

Another study on prebiotic effects of Xylooligosaccharides on the improvement of microbiota balance in human subjects reported that the abundance of pathogenic bacteria, Clostridium perfringens, was significantly lower in the fecal samples of the XOS group than in those of the control group. This was explained by the XOS suppressing the growth of Clostridium perfringens; the mechanisms underlying this effect were likely due to the production of short-chain fatty acids (SCFAs) via the fermentation of XOS in the colon. A decrease in intestinal $\mathrm{pH}$ has been reported because of the increased SCFA production which subsequently inhibits the overgrowth of pathogenic bacteria [8].

A comparative study of synbiotic and prebiotic supplementation on gut health, SCFA, hsCRP and lipid profile of type-2 diabetic subjects with pre-hypertension concluded that daily intake of $1 \mathrm{~g}$ synbiotic product and $10 \mathrm{ml}$ FOS improved gut health, hs-CRP, lipid profile and short chain fatty acids (SCFA) of the subjects which may be due to increased production of SCFA [7].

Another study on consumption of XOS in combination with inulin did not decrease the concentrations of acetate and $p$-cresol but increased the faecal concentrations of total SCFA and propionate [18].

In this study, as shown in figure 2, 3 and 4, Acetate was produced the most followed by Propionate and Butyrate. Bifidobacterium adolescentis produced (331\%) more of Butyrate and Propionate respectively on its exposure to XOS ( $\mathrm{p} \leq 0.01$ ), whereas, Lactobacillus plantarum produced more acetate as compared to Bifidobacterium adolescentis $(\mathrm{p} \leq 0.001)$. Production of all the three SCFA reduced (20\%-48\%) in case of Escherichia coli on its exposure to XOS $(\mathrm{p} \leq 0.001)$. In case of fermentation of XOS and glucose into butyrate, acetate and propionate on exposure to Lactobacillus plantarum and Escherichia coli, $1 \%$ of XOS and glucose samples were used as it gave the maximum O.D. when compared to $0.5 \%$ and $2 \%$. Similarly, for Bifidobacterium adolescentis $2 \%$ XOS and glucose samples were used as it gave maximum O.D. 

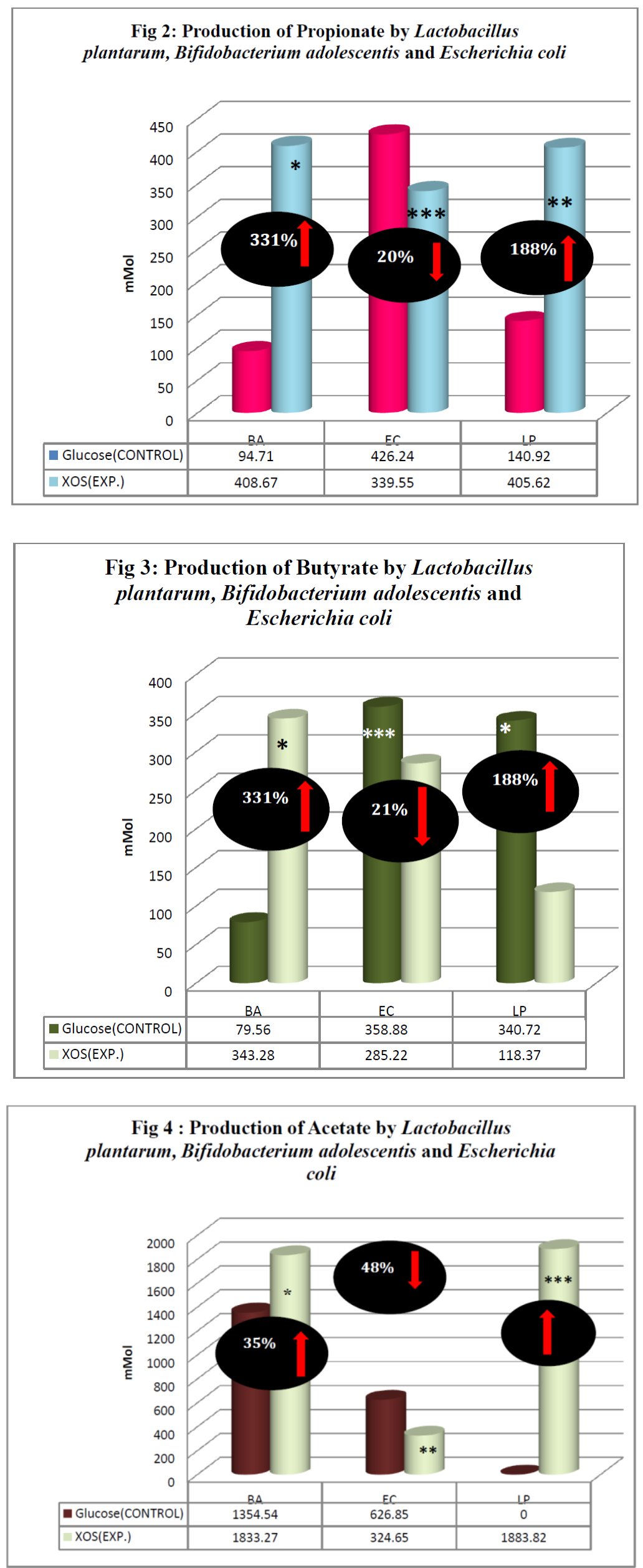

Significant at $* \mathrm{p} \leq 0.05,{ }^{* *} \mathrm{p} \leq 0.01,{ }^{* * *} \mathrm{p} \leq 0.001$ 


\section{Organoleptic evaluation of color rice kheer and Prawn patia}

The organoleptic scores of Black rice kheer and Prawn patia prepared by substituting sugar with varying levels of XOS are presented in Table 2. F test revealed no significant difference in XOS added Black rice kheer and Prawn patia at all levels of addition (5\%, 8\% and 10\%). Hence, XOS addition to these two products was well accepted by the panellists up to $10 \%$ level of addition.

Table 2: Effect of varying levels of XOS substitution on the organoleptic qualities of Black rice kheer and Prawn patia

\begin{tabular}{|c|c|c|c|c|c|c|c|c|c|c|}
\hline & \multicolumn{5}{|c|}{ BLACK RICE KHEER } & \multicolumn{5}{|c|}{ PRAWN PATIA } \\
\hline $\begin{array}{l}\text { Levels } \\
\text { of XOS }\end{array}$ & $\begin{array}{l}\text { Color and } \\
\text { Appearance } \\
(\text { mean } \pm \text { SD) }\end{array}$ & $\begin{array}{l}\text { Texture } \\
\text { (mean } \pm \\
\text { SD) }\end{array}$ & $\begin{array}{l}\text { Taste and } \\
\text { Mouthfeel } \\
(\text { mean } \pm \text { SD) }\end{array}$ & $\begin{array}{l}\text { After } \\
\text { Taste } \\
(\text { mean } \\
\pm \text { SD) }\end{array}$ & $\begin{array}{l}\text { Overall } \\
\text { acceptabil } \\
\text { ity(mean } \pm \\
\text { SD) }\end{array}$ & $\begin{array}{l}\text { Color and } \\
\text { Appearance } \\
(\text { mean } \pm \text { SD })\end{array}$ & $\begin{array}{l}\text { Texture } \\
(\text { mean } \pm \\
\text { SD) }\end{array}$ & $\begin{array}{l}\text { Taste and } \\
\text { Mouthfeel } \\
(\text { mean } \pm \text { SD) }\end{array}$ & $\begin{array}{l}\text { After } \\
\text { Taste } \\
\text { (mean } \\
\pm \text { SD) }\end{array}$ & $\begin{array}{c}\text { Overall } \\
\text { acceptability } \\
(\text { mean } \pm \text { SD })\end{array}$ \\
\hline $0 \%$ & $8.76 \pm 0.65$ & $\begin{array}{l}8.36 \pm \\
1.20\end{array}$ & $8.80 \pm 0.90$ & $\begin{array}{l}8.64 \pm \\
0.93\end{array}$ & $8.6 \pm 1.20$ & $8.88 \pm 1.12$ & $\begin{array}{l}9.01 \pm \\
1.27\end{array}$ & $8.4 \pm 1.06$ & $\begin{array}{l}8.46 \pm \\
0.84\end{array}$ & $8.52 \pm 0.84$ \\
\hline $5 \%$ & $7.92 \pm 1.30$ & $\begin{array}{l}8.6 \pm \\
1.24 \\
\end{array}$ & $8.28 \pm 1.35$ & $\begin{array}{l}8.12 \pm \\
1.25 \\
\end{array}$ & $8.44 \pm 1.10$ & $9.01 \pm 0.93$ & $\begin{array}{l}9.22 \pm \\
0.84\end{array}$ & $8.16 \pm 0.87$ & $\begin{array}{l}8.53 \pm \\
0.70\end{array}$ & $8.61 \pm 0.56$ \\
\hline $8 \%$ & $8.04 \pm 1.49$ & \begin{tabular}{|l|l|}
$8.48 \pm$ \\
1.10 \\
\end{tabular} & $7.88 \pm 1.11$ & $\begin{array}{l}8.00 \pm \\
0.98 \\
\end{array}$ & $7.72 \pm 1.00$ & $8.66 \pm 1.34$ & $\begin{array}{l}9.24 \pm \\
0.76 \\
\end{array}$ & $8.0 \pm 1.83$ & $\begin{array}{l}8.50 \pm \\
0.74 \\
\end{array}$ & $8.46 \pm 1.13$ \\
\hline $10 \%$ & $7.64 \pm 1.60$ & $\begin{array}{l}8.56 \pm \\
1.02\end{array}$ & $7.16 \pm 1.05$ & $\begin{array}{l}7.08 \pm \\
1.27\end{array}$ & $7.40 \pm 1.27$ & $9.12 \pm 1.03$ & $\begin{array}{l}9.22 \pm \\
0.84\end{array}$ & $8.33 \pm 1.93$ & $\begin{array}{l}8.58 \pm \\
0.83\end{array}$ & $8.65 \pm 1.33$ \\
\hline $\begin{array}{l}\text { F - } \\
\text { Value }\end{array}$ & 1.14 & 1.59 & 1.07 & 1.01 & 1.08 & 2.11 & 2.47 & 1.29 & 1.61 & 1.66 \\
\hline $\begin{array}{l}p- \\
\text { value }\end{array}$ & $0.32^{\mathrm{NS}}$ & $0.25^{\mathrm{NS}}$ & $0.34^{\mathrm{NS}}$ & $0.35^{\mathrm{NS}}$ & $0.33^{\mathrm{NS}}$ & $0.19^{\mathrm{NS}}$ & $0.16^{\mathrm{NS}}$ & $0.29^{\mathrm{NS}}$ & $0.25^{\mathrm{NS}}$ & $0.24^{\mathrm{NS}}$ \\
\hline
\end{tabular}

However, difference test conducted to determine if the products judged were superior, equal or inferior to the standard product $(0 \%$ XOS) with varying levels of XOS revealed that most of the panelists found color of the Black rice kheer to be superior or equal to the standard $(\mathrm{p} \leq 0.01)$ at all the three levels of addition. The overall acceptability and other sensory attributes of Black rice kheer were equal or superior at $8 \%$ level and addition of $10 \%$ levels of XOS rendered Black rice kheer less sweet. This data indicated that XOS improved most of the organoleptic attributes up to $8 \%$ levels of addition (Table 3 ).

As seen in table 4, the difference test revealed that the sensory attributes of Prawn patia with different levels of addition of XOS were either superior or equal to the standard product $(\mathrm{p} \leq 0.001)$.

A study conducted on development and sensory analysis of a buttermilk based fermented beverage using barley and fructooligosaccharide as functional ingredients reported high scores for overall acceptability and the sweet taste of FOS did not negatively affect the taste, aftertaste and mouthfeel of the product [19]. Another study conducted on FOS added beverages and soup namely, butter milk, lemon juice, milk and tomato soup at 2.5\%, 4\%, 5\%, 6\%, 7.5\% showed positive results on the overall acceptability of the products [20]. Similar results were reported by Parnami et al, where cookies and bread were fortified with prebiotic inulin [21].

A study on Xylooligosaccharide enriched yoghurt reported that addition of XOS up to $3.5 \%$ did not influence taste and overall acceptability but higher levels of addition resulted in lower after taste scores [22]. 
Table 3: Number of panel members indicating the difference in the organoleptic attributes of Black rice kheer in a difference test.

\begin{tabular}{|c|c|c|c|c|c|c|c|c|c|c|c|c|c|c|c|c|}
\hline \multirow{3}{*}{$\begin{array}{c}\text { Level of } \\
\text { substitution }\end{array}$} & \multicolumn{16}{|c|}{ SENSORY ATTRIBUTES } \\
\hline & \multicolumn{4}{|c|}{ Color and appearance } & \multicolumn{4}{|c|}{ Taste and mouthfeel } & \multicolumn{3}{|c|}{ After taste } & \multirow[b]{2}{*}{$\begin{array}{l}\text { Chi sq } \\
\text { value }\end{array}$} & \multicolumn{4}{|c|}{ Overall acceptability } \\
\hline & Superior & Equal & Inferior & $\begin{array}{l}\text { Chi sq } \\
\text { value }\end{array}$ & $\begin{array}{l}\text { Superi } \\
\text { or }\end{array}$ & Equal & Inferior & $\begin{array}{l}\text { Chi sq } \\
\text { value }\end{array}$ & $\begin{array}{l}\text { Superi } \\
\text { or }\end{array}$ & Equal & Inferior & & $\begin{array}{l}\text { Supe } \\
\text { rior }\end{array}$ & Equal & Inferior & $\begin{array}{l}\text { Chi sq } \\
\text { value }\end{array}$ \\
\hline $5 \%$ & 0 & 32 & 43 & & 6 & 63 & 6 & & 31 & 32 & 12 & & 31 & 44 & 0 & \\
\hline & & & & $0.01^{* *}$ & & & & $5.21^{* * * *}$ & & & & $1.01^{* * *}$ & & & & $4.58^{* * *}$ \\
\hline $8 \%$ & 0 & 32 & 43 & & 25 & 35 & 15 & & 0 & 42 & 33 & & 9 & 57 & 0 & \\
\hline $10 \%$ & 6 & 32 & 37 & & 25 & 10 & 40 & & 22 & 20 & 33 & & 6 & 22 & 47 & \\
\hline
\end{tabular}

Level of significance in increasing order- $(* \mathrm{p}<0.05, * * \mathrm{p}<0.01, * * * \mathrm{p}<0.001)$; NS- Nonsignificant

Table 4: Number of panel members indicating the difference in the organoleptic attributes of Prawn patia in a difference test.

\begin{tabular}{|c|c|c|c|c|c|c|c|c|c|c|c|c|c|c|c|c|}
\hline \multirow{3}{*}{$\begin{array}{l}\text { Level of } \\
\text { substitution }\end{array}$} & \multicolumn{16}{|c|}{ SENSORY ATTRIBUTES } \\
\hline & \multicolumn{4}{|c|}{ Color and appearance } & \multicolumn{3}{|c|}{ Taste and Mouthfeel } & \multicolumn{5}{|c|}{ After taste } & \multicolumn{4}{|c|}{ Overall acceptability } \\
\hline & Superior & Equal & Inferior & $\begin{array}{l}\text { Chi sq } \\
\text { value }\end{array}$ & $\begin{array}{l}\text { Superi } \\
\text { or }\end{array}$ & Equal & Inferior & $\begin{array}{l}\text { Chi sq } \\
\text { value }\end{array}$ & $\begin{array}{l}\text { Superi } \\
\text { or }\end{array}$ & Equal & Inferior & Chi sq value & $\begin{array}{l}\begin{array}{l}\text { Supe } \\
\text { rior }\end{array}\end{array}$ & Equal & Inferior & $\begin{array}{l}\text { Chi sq } \\
\text { value }\end{array}$ \\
\hline $5 \%$ & 0 & 69 & 6 & & 0 & 69 & 6 & & 12 & 63 & 0 & & 12 & 63 & 0 & \\
\hline & & & & $0.001^{* * *}$ & & & & $1.69^{* * *}$ & & & & $0.0006^{* * *}$ & & & & $7.04^{* * * *}$ \\
\hline $8 \%$ & 12 & 63 & 0 & & 36 & 24 & 15 & & 12 & 48 & 15 & & 24 & 36 & 15 & \\
\hline $10 \%$ & 6 & 63 & 6 & & 36 & 21 & 18 & & 6 & 54 & 15 & & 24 & 33 & 18 & \\
\hline
\end{tabular}

Level of significance in increasing order- $(* \mathrm{p}<0.05, * * \mathrm{p}<0.01, * * * \mathrm{p}<0.001)$; NS- Nonsignificant 
CONCLUSION: The prebiotic potential of XOS in terms of acid tolerance, bile resistance, growth of probiotic bacteria and production of SCFA was successfully established in this study. XOS was well accepted by the panel members in both the products up to $10 \%$ indicating that many foods may be enriched with XOS as a prebiotic. Hence, this study has created a strong evidence-based data to prove the prebiotic potential of XOS. However, further studies can be undertaken to demonstrate the clinical efficacy of XOS intake with respect to various non communicable diseases.

List of Abbreviations: XOS- Xylooligosaccharide, FOS- Fructooligosaccharide, GOSGalactooligosaccharide, SCFA- Short chain fatty acid.

Competing Interests: There are no conflicts of interest to declare.

Author's Contributions: Both the authors contributed to this study.

Acknowledgments: This study was partially funded by The M.S. University of Baroda under the University Research Scholarship. The in vitro prebiotic property phase was performed at Nirma University, Ahmedabad, Gujarat, India and organoleptic evaluation of the products were performed at The Institute of Hotel Management, Catering Technology and Applied Nutrition, Guwahati, Assam, India. We thank Dr. Sriram Seshadri and Dr. Amitabh Dey for allowing us to perform our research at their respective Institute.

\section{REFERENCES}

1. Aachary AA, Prapulla SG: Xylooligosaccharides (XOS) as an emerging prebiotic: microbial synthesis, utilization, structural characterization, bioactive properties, and applications. Comprehensive Reviews in Food Science and Food Safety. 2011 10(1): 216.

2. Gibson GR, Probert HM, Van-Loo JAE: Dietary modulation of the human colonic microbiota: updating the concept of prebiotics. Nutr Res Rev. 2004 17: 259-275.

3. Courtin CM, Swennen K, Verjans P, Delcour J: Heat and pH stability of prebiotic arabinoxylooligosaccharides, xylooligosaccharides and fructooligosaccharides. Food chemistry. 2009 112(4): 831 - 837.

4. Hutkins RW, Krumbeck JA, Bindels LB, Cani PD, Fahey G Jr, Goh YJ, Hamaker B, et al.: Prebiotics: why definitions matter. Curr Opin Biotechnol. 2016 37:1-7.

5. Bindels LB, Neyrinck AM, Salazar N, Taminiau B, Druart C, Muccioli GG, François E, et al.: Non-Digestible Oligosaccharides Modulate the Gut Microbiota to Control the Development of Leukemia and Associated Cachexia in Mice. PLoS ONE 2015 .10(6).

6. Rycroft CE, Jones MR, Gibson GR, Rastall RA: A comparative in vitro evaluation of the fermentation properties of prebiotic oligosaccharides. J Appl Microbiol. 2001 91(5): 878887.

7. Sheth M, Khan M R, Dehingia M, Thakuria A, Chand V: A comparative study of synbiotic and prebiotic supplementation on gut health, SCFA, hs-CRP and lipid profile of type 2 diabetic subjects with pre-hypertension. European Journal of Biomedical and Pharmaceutical sciences. 2015 3(1): 148-155. 
8. Lin SH, Chou LM, Chien YW, Chang JS, Lin CI: Prebiotic Effects of Xylooligosaccharides on the Improvement of Microbiota Balance in Human Subjects. Gastroenterology Research and Practice. 2016 1-6.

9. Rangana $S$ : Handbook of analysis and quality control of fruit and vegetable products. 11th Ed, McGraw Hill Publishing Co. Ltd, New Delhi, 1986.

10. Adaptation and Validation of Food Product Specific Analytical Methods for Monitoring Prebiotics Present in Different Types of Processed Food Matrices - Dissertations, Theses, and Student Research in Food Science and Technology [http://digitalcommons.unl.edu/foodscidiss/21] Accessed on June 26, 2018.

11. Yen YH, Chia ML, Ming CW: Evaluation of the prebiotic effects of citrus pectin hydrolysate. Journal of Food and Drug Analysis. 2017 25(3): 550-558.

12. Cummings JH, Macfarlane GT, Englyst HN: Prebiotic digestion and fermentation. American Journal of Clinical Nutrition (Suppl.) 2001 73: 415-420.

13. Huebner J, Wehling RL, Hutkins RL: Functional Activity of Commercial Prebiotics. International Dairy Journal. 2007 17(7): 770-775.

14. Mandalari G, Bennett R, Kirby AR, Lo Curto RB, Bisignano G, Waldron KW and Faulds $\mathrm{CB}$ : Enzymatic hydrolysis of flavonoids and pectic oligosaccharides from bergamot (Citrus bergamia Risso) peel. Journal of Agricultural and Food Chemistry. 2006 54: 8307-8313.

15. Pedraza L, Toribio H, Romo R, Arreola S, Guevara M: Journal of Chemical, Biological and Physical Sciences. 2014 4(5): 1-5.

16. Grootaert C, Delcour JA, Courtin CM, Broekaert WF, Verstraete W, Van de WT: Microbial metabolism and prebiotic potency of arabinoxylan oligosaccharides in the human intestine. Trends in Food Science and Technology. 2007 18(2): 64-71.

17. Manisseri C, Gudipati M: Bioactive xylo-oligosaccharides from wheat bran soluble polysaccharides. LWT - Food Science and Technology. 2009 43:421-430.

18. Lecerf JM, Depeint F, Clerc E, Dugenet Y, Niamba CN, Rhazi L, Cayzeele A: Xylooligosaccharide (XOS) in combination with inulin modulates both the intestinal environment and immune status in healthy subjects, while XOS alone only shows prebiotic properties. British Journal of Nutrition. 2012 108(10): 1847-58.

19. Sheth M, Hirdyani H: Development and sensory analysis of a buttermilk based fermented drink using barley and fructo-oligosaccharide as functional ingredients. International Journal of Home Science. 2016 2: 235-239.

20. Neha G, Mini S: Acceptability trials of fructooligosaccharides (FOS) added soup and beverages. Asian journal of homescience. 2011 6(2):131-136.

21. Parnami S, Sheth M: Inulin as prebiotic in bread and cookies- a feasibility study. Inventi Rapid: Nutraceuticals. 2010 1(3).

22. Mumtaz, S, Rehman, SU, Huma, N, Jamil A, Nawaz H: Xylooligosaccharide enriched yoghurt: physicochemical and sensory evaluation. Pakistan Journal of Nutrition, 2008 7(4): 566-569. 